\title{
Olanzapine Versus Placebo and Haloperidol: Quality of Life and Efficacy Results of the North American Double-Blind Trial
}

\author{
Susan H. Hamilton, M.S., Dennis A. Revicki, Ph.D., Laura A. Genduso, Pharm.D., \\ and Charles M. Beasley, Jr., M.D.
}

\begin{abstract}
This double-blind study evaluated the impact of treatment with olanzapine compared with haloperidol, and placebo on improvements in symptomatology and quality of life in patients with a DSM-III-R diagnosis of schizophrenia. A total of 335 patients was randomized to five treatment groups; olanzapine $5 \pm 2.5 \mathrm{mg} /$ day, olanzapine $10 \pm 2.5$ $\mathrm{mg} /$ day, olanzapine $15 \pm 2.5 \mathrm{mg} /$ day, haloperidol $15 \pm 5$ $\mathrm{mg} /$ day, and placebo. Patients responding to treatment during the 6-week acute phase were eligible to enter a 46-week extension. Efficacy measures included the brief psychiatric rating scale total, scale for assessment of negative symptoms summary, and clinical global
\end{abstract}

impressions severity scores. Quality of life was evaluated using the quality of life scale. Data analyzed after 24 weeks of therapy showed that olanzapine was significantly superior to placebo in reducing clinical severity and significantly superior to haloperidol in reducing negative symptoms in patients responding to acute treatment. Furthermore, improvement in quality of life was observed in olanzapine-treated responders.

[Neuropsychopharmacology 18:41-49, 1998] (C) 1998 American College of Neuropsychopharmacology. Published by Elsevier Science Inc.
KEY WORDS: Double-blind method; Haloperidol;

Antipsychotic agents; Schizophrenia; Quality of life

Whereas the psychopathy associated with schizophrenia includes both positive and negative symptoms, the quality of life of patients with schizophrenia is becoming increasingly important in the evaluation of antipsychotic drugs. Comprehensive evaluations of new psychopharmacologic agents and mental health interventions require both the clinical assessment of changes in psychopathology and the assessment of quality of life

From Lilly Research Laboratories, (SHH, LAG, CMB), Indianapolis, Indiana; and MEDTAP International (DAR), Bethesda, Maryland.

Address correspondence to: Susan H. Hamilton, M.S., Eli Lilly and Company, Lilly Research Laboratories, Lilly Corporate Center 0537, Indianapolis, IN 46285.

Received March 7, 1997; revised May 8, 1997; accepted June 10, 1997
(Awad 1992; Lehman et al. 1993; Revicki and Murray 1994). Several reviews of clinical trial outcomes have found that although all trials included assessments of positive symptomatology, few studies evaluated negative symptoms or quality of life outcomes (Carpenter et al. 1981; Collins et al. 1991).

Quality of life, specifically health-related quality of life, can be defined as the value assigned to duration of life as modified by the impairments, functional states, perceptions, and social opportunities that are influenced by disease, injury, treatment, or policy (Patrick and Erickson 1993). Quality of life measurements have been used in patients with schizophrenia to assess community needs and are increasingly being used to assess treatment interventions in clinical trials (Awad et al. 1997). Both generic and disease-specific quality of life instruments are available for assessing the outcomes of schizophrenia treatments. The quality of life scale 
(Heinrichs et al. 1984), the quality of life interview (Lehman et al. 1986), and the Wisconsin quality of life scale (Becker et al. 1993) are being used in clinical trials. There are numerous challenges in collecting quality of life data from patients with schizophrenia and also multiple ways to collect the data, including patient and clinician reports.

Conventional antipsychotic drugs are effective in alleviating positive symptoms; however, many patients continue to experience negative symptoms as manifested by reduced functioning and well-being. In addition, these drugs are associated with movement disorders and other serious side effects (Kane and Marder 1993). Because of these limitations, there is a continued search for new antipsychotics with broad clinical efficacy and little or no side effects. Clozapine has proven effective in treating chronic schizophrenia (Kane et al. 1988; Meltzer et al. 1990; Breier et al. 1994), but the rate of seizures, agranulocytosis, and other troublesome side effects have restricted clozapine's use to patients with psychopathology resistant to conventional neuroleptic treatment. Risperidone appears to be safe and clinically effective, with some improvement in negative symptom efficacy (Marder and Meibach 1994, Chouinard et al. 1993) and few extrapyramidal symptoms (Marder and Meibach 1994).

More recently, olanzapine has been shown to be an effective treatment for schizophrenia (Tollefson et al. 1997, Beasley et al. 1996a,b). Olanzapine, a thienobenzodiazepine, is a putative atypical antipsychotic and a potent $5-\mathrm{HT}_{2 \mathrm{~A} / 2 \mathrm{C}}$ and dopamine $\mathrm{D}_{4} \mathrm{D}_{1 /} \mathrm{D}_{2}$ antagonist with anticholinergic activity (Moore et al. 1993, 1994). This study was designed to evaluate the effect of three different olanzapine dosages compared with placebo and haloperidol on improvement in symptomatology and quality of life outcomes. Because olanzapinetreated patients demonstrated superior short-term efficacy compared with placebo- and haloperidol-treated patients, it was hypothesized that these results would persist long-term. Furthermore, it was hypothesized that the superior efficacy and safety profile of olanzapine would contribute to greater quality of life in olanzapine-treated patients compared with haloperidoland placebo-treated patients.

\section{METHODS}

\section{Study Design}

A total of 335 male and female aged 18 to 65 years with DSM-III-R documented schizophrenia (American Psychiatric Association 1987) with an acute exacerbation from 23 clinical centers was included in this study. Acute phase efficacy and safety results have previously been reported (Beasley et al. 1996a). Patients were re- quired to have a brief psychiatric rating scale-anchored (BPRS) (Woerner et al. 1988) total score (items scored 0 to 6) of at least 24. Patients were excluded if they had DSM-III-R organic mental or substance use disorders active within 3 months of study entry or were at serious suicidal risk. Patients were required to be off oral neuroleptics for at least 2 days and off depot neuroleptics for at least 6 weeks before study entry. All patients gave written informed consent before entering the study. The study protocol was approved by each center's institutional review board.

Patients discontinued all antipsychotic medications and entered a single-blind, placebo lead-in period of 4 to 7 days. Patients whose BPRS total scores decreased $>25 \%$ or whose BPRS total score decreased to $<24$ during the placebo lead-in phase were discontinued as placebo responders. After the placebo lead-in phase, patients eligible to continue the study were randomized at baseline to one of five treatment groups: olanzapine $5 \pm$ $2.5 \mathrm{mg}$ / day (Olz-L), olanzapine $10 \pm 2.5 \mathrm{mg} /$ day (Olz$\mathrm{M})$, olanzapine $15 \pm 2.5 \mathrm{mg} /$ day $(\mathrm{Olz}-\mathrm{H})$, haloperidol $15 \pm 5 \mathrm{mg} /$ day (Hal), or placebo. Patients began treatment with the middle dose of their assigned dosage range. The dose could be increased or decreased as clinically indicated. Upward adjustment could occur at any regularly scheduled visit. Downward adjustment could occur at any time. Lorazepam (up to $10 \mathrm{mg} /$ day) was allowed if a sedative was needed, and benzotropine mesylate (up to $6 \mathrm{mg} /$ day) was allowed to control extrapyramidal symptoms. Patients received usual care with regard to vocational and psychosocial support.

Patients remained hospitalized during the placebo lead-in and the first 2 weeks of double-blind therapy. For the next 4 weeks, patients could be inpatients or outpatients. Once released to outpatient status, patients were to remain outpatients. Rehospitalization did not necessitate withdrawal of the patient from the study. Patients could be discharged to outpatient status if their BPRS total score decreased $>25 \%$ from baseline (randomization) or was $<24$, and they were judged capable of functioning safely in an outpatient setting. The duration of the double-blind acute phase was 6 weeks. Patients were eligible to enter the double-blind extension if they were responding to treatment at the completion of the acute phase, were experiencing no serious adverse effects, and if the clinical investigator thought continued treatment was clinically warranted. Patients not responding to therapy (nonresponders) discontinued from the study at the end of the acute phase. Response was defined as either a $>40 \%$ decrease from baseline in BPRS total score or a BPRS total score $<18$. If arrangements to place a patient in an outpatient living situation were not made by the end of the acute phase, the patient was permitted to enter the double-blind extension and continue as an inpatient for up to 4 additional weeks. If the patient still did not have outpatient 
living accommodations, the patient was discontinued from the study.

This article addresses the efficacy and quality of life outcomes over the first 24 weeks of the study. Results were based on patients responding to acute treatment. Quality of life evaluations were not analyzed past 24 weeks because of very small sample sizes (three to 15 per treatment group for the 36-week assessment and three to 12 patients per treatment group for the 52-week assessment).

The BPRS, scale for the assessment of negative symptoms (SANS) (Andreasen 1982), and the clinical global impressions-severity (CGI severity) (Guy 1976) were used to evaluate changes in overall and negative symptomatology and were administered at baseline and all scheduled visits. All data collection was performed by trained clinicians.

Quality of life outcomes for patients with schizophrenia have been evaluated using a number of different measures (Lehman and Burns 1990; Revicki and Murray 1994). In this study, the quality of life scale (QLS) was used because the QLS is a disease-specific quality of life measure of schizophrenic deficit syndrome or enduring negative symptoms (Heinrichs et al. 1984). The QLS has been used in studies assessing the relationship between negative symptoms and prognosis in quality of life and social adjustment (Bellack et al. 1990; Mueser et al. 1991) as well as in continuous versus targeted medication in schizophrenia outpatients (Carpenter et al. 1990). In an open-label 6-month clozapine study in patients with treatment-resistant schizophrenia, the QLS was used and indicated a favorable response (Meltzer et al. 1990). Olanzapine, an atypical antipsychotic agent, exhibits improvements in negative symptoms compared with typical agents, such as haloperidol. Therefore, the QLS, a quality of life scale that focuses on negative symptoms, was chosen.

The QLS is a semi-structured interview administered and rated by trained clinicians. Although self-report measurement may be preferable, it may not be possible in patients with significant thought disturbances and cognitive impairment. It contains 21 items rated on a 7-point scale based on the interviewer's judgement of patient functioning. A total QLS and four subscale scores are calculated, with higher scores indicating less impairment. The four subscale scores are intrapsychic foundations, interpersonal relations, instrumental role category, and common objects and activities. Intrapsychic foundations (six items) evaluates a patient's cognition, conation, and affectivity. Interpersonal relations (eight items) measures different aspects of social relations and interpersonal experience. Instrumental role category (four items) focuses on various social roles such as student, housekeeper, or worker. Common objects and activities (two items) assumes that participations in the community is reflected in the possession of common objects and engagement in a range of regular activities. The QLS has acceptable reliability (Heinrichs et al. 1984). Intraclass correlations range from 0.53 to 0.94 for individual items and range from 0.88 to 0.97 for the four subscales and total scores. Lehman and colleagues (1993) provide support for the convergent validity of the QLS by showing significant correlations between QLS subscales and relevant subscales on the quality of life interview. The QLS was administered at baseline for all patients and at weeks 12 and 24 for patients responding to treatment. No postbaseline QLS scores were available for nonresponders.

\section{Statistical Analysis}

Treatment group differences on baseline demographics, illness characteristics, and QLS scores were evaluated by using $\chi^{2}$ tests for categorical data and analysis of variance (ANOVA) for continuous data. The ANOVA model contained the term treatment. Differences in treatment discontinuation rates and study completion rates were evaluated by using $\chi^{2}$ tests.

Change from baseline to the week 24 score (last observation carried forward [LOCF]) was calculated for the efficacy and QLS scores. Of the 335 randomized patients, $76(23 \%)$ had both a baseline and a postbaseline QLS score. Both within-treatment group and betweentreatment group LOCF changes from baseline to endpoint were evaluated. The within-treatment group changes were evaluated using Wilcoxon signed rank tests. Between-treatment group changes were evaluated by ANOVA to compare the Olz-L, Olz-M, Olz-H, and Hal treatment groups with the placebo treatment group and the three olanzapine treatment groups with the Hal treatment group. The ANOVA model contained the terms treatment and investigator.

Baseline differences between treatment responders and nonresponders, regardless of treatment group, were compared by using $\chi^{2}$ tests for categorical variables and ANOVA for continuous variables. The ANOVA model contained the term responder (yes/no).

In an exploratory analysis, analysis of covariance (ANCOVA) was used to compare the LOCF change from baseline to week 24 in QLS scores among the five treatment groups after substituting estimates of endpoint QLS scores for treatment nonresponders. The ANCOVA model contained the terms treatment and investigator as well as the covariate baseline QLS score. To account for the missing QLS scores for patients not showing a response at the end of the acute phase, an assumption was made that these patients' QLS scores would be unchanged from baseline (zero change from baseline).

A two-tailed 0.05 level of significance was used for all statistical tests. No adjustment was made for multiple comparisons. 


\section{RESULTS}

\section{Baseline Characteristics}

Demographic and illness characteristics and QLS scores for responders with a baseline and at least one followup QLS total score are summarized in Table 1. No significant differences were observed among the treatment groups with respect to demographics and baseline BPRS, CGI severity, and QLS scores; however, a significant difference was found for SANS summary scores. The Olz-H treatment group had the highest mean SANS summary score, reflecting greater negative symptom severity at baseline compared with the other treatment groups.

The Olz-M treatment group differed from the other treatment groups since this group was over 4 years older, had a greater percentage of the paranoid subtype, had a smaller percentage with $<10$ previous episodes, and had lower baseline quality of life total, intrapsychic foundations, and interpersonal relations scores.

\section{Patient Disposition}

Patient disposition for patients responding to doubleblind therapy at the end of the acute phase who continued into the responder extension is shown in Table 2.
No significant differences were observed among the treatment groups. The completion rates in the olanzapine treatment groups were over twice those observed in the placebo and Hal treatment groups.

Discontinuations due to adverse events were lower in the olanzapine treatment groups than in the placebo and Hal treatment groups. The discontinuation rate due to lack of efficacy in the placebo group was over twice the rates observed in the other treatment groups.

\section{Efficacy}

Mean changes from baseline to week 24 (LOCF) in the efficacy rating scales are summarized for responders in Table 3. There were significant within-treatment group improvements in BPRS total scores in all but the placebo treatment group. The Olz-M, Olz-H, and Hal treatment groups showed significant mean improvement in BPRS total score compared with the placebo group. No significant differences in BPRS total scores were observed between the Hal treatment group and the olanzapine treatment groups. Significant within-treatment group improvement in negative symptoms based on the SANS summary score was observed in the Olz-M, $\mathrm{Olz}-\mathrm{H}$, and $\mathrm{Hal}$ treatment groups. The $\mathrm{Olz}-\mathrm{H}$ treatment

Table 1. Baseline Demographics, Illness Characteristics, and Quality of Life Scale Scores: Patients with a Baseline and Postbaseline Quality of Life Score

\begin{tabular}{|c|c|c|c|c|c|c|}
\hline Variable & $\begin{array}{l}\text { Placebo } \\
(n=10)\end{array}$ & $\begin{array}{l}\text { Olz-L } \\
(n=16)\end{array}$ & $\begin{array}{c}\text { Olz-M } \\
(n=16)\end{array}$ & $\begin{array}{c}\text { Olz-H } \\
(n=22)\end{array}$ & $\begin{array}{c}\text { Hal } \\
(n=12)\end{array}$ & $\begin{array}{c}\text { Overall } \\
p \text {-Value }^{a}\end{array}$ \\
\hline Male $(\%)$ & 70.0 & 93.8 & 87.5 & 72.7 & 100.0 & .127 \\
\hline Caucasian $(\%)$ & 80.0 & 68.8 & 68.8 & 90.9 & 66.7 & .367 \\
\hline Age, years (mean $\pm \mathrm{SD})$ & $36.1 \pm 8.9$ & $33.5 \pm 9.1$ & $40.9 \pm 11.4$ & $34.4 \pm 9.0$ & $36.1 \pm 11.8$ & .260 \\
\hline \multicolumn{7}{|l|}{ Subtype } \\
\hline Paranoid (\%) & 60.0 & 56.3 & 68.8 & 50.0 & 50.0 & .879 \\
\hline Disorganized (\%) & 0.0 & 12.5 & 12.5 & 9.1 & 8.3 & \\
\hline Undifferentiated (\%) & 40.0 & 31.3 & 18.8 & 40.9 & 41.7 & \\
\hline Chronic course, $\mathrm{AE}(\%)$ & 80.0 & 81.3 & 87.5 & 81.8 & 83.3 & .986 \\
\hline \multicolumn{7}{|l|}{ Age of psychosis onset, years } \\
\hline$($ mean $\pm S D)$ & $25.5 \pm 7.8$ & $23.3 \pm 6.9$ & $24.3 \pm 8.4$ & $24.1 \pm 6.2$ & $23.2 \pm 6.4$ & .939 \\
\hline$<10$ Previous episodes (\%) & 70.0 & 73.3 & 53.3 & 65.0 & 80.0 & .665 \\
\hline $\mathrm{BPRS}$ total $($ mean $\pm \mathrm{SD})$ & $34.3 \pm 10.3$ & $36.8 \pm 7.9$ & $40.9 \pm 9.1$ & $40.8 \pm 10.0$ & $36.5 \pm 10.7$ & .268 \\
\hline SANS summary (mean \pm SD) & $10.2 \pm 3.5$ & $11.9 \pm 3.9$ & $11.8 \pm 4.2$ & $14.1 \pm 3.7$ & $10.5 \pm 4.2$ & .044 \\
\hline CGI severity (mean $\pm \mathrm{SD})$ & $4.2 \pm 0.4$ & $4.7 \pm 0.8$ & $4.8 \pm 0.9$ & $4.8 \pm 0.9$ & $4.8 \pm 0.6$ & .339 \\
\hline QLS total (mean $\pm \mathrm{SD})$ & $58.6 \pm 19.5$ & $52.4 \pm 23.9$ & $42.9 \pm 20.4$ & $49.8 \pm 21.2$ & $48.6 \pm 17.9$ & .443 \\
\hline \multicolumn{7}{|l|}{ QLS intrapsychic foundations } \\
\hline$($ mean \pm SD) & $22.8 \pm 5.7$ & $19.1 \pm 7.6$ & $16.5 \pm 7.3$ & $19.0 \pm 6.8$ & $18.7 \pm 4.9$ & .254 \\
\hline $\begin{array}{l}\text { QLS interpersonal relations } \\
(\text { mean } \pm \mathrm{SD})\end{array}$ & \multicolumn{5}{|c|}{ QLS interpersonal relations } & .692 \\
\hline \multicolumn{7}{|l|}{ QLS instrumental role category } \\
\hline$($ mean $\pm S D)$ & $10.0 \pm 7.0$ & $7.3 \pm 8.0$ & $5.1 \pm 5.5$ & $6.0 \pm 6.4$ & $4.9 \pm 6.6$ & .356 \\
\hline $\begin{array}{l}\text { QLS common objects and activities } \\
(\text { mean } \pm \text { SD })\end{array}$ & $8.6 \pm 1.8$ & $6.6 \pm 2.3$ & $6.3 \pm 3.5$ & $6.4 \pm 2.4$ & $6.1 \pm 2.1$ & .144 \\
\hline
\end{tabular}

Abbreviations: Olz-L = olanzapine treatment range, 2.5, 5, or $7.5 \mathrm{mg} /$ day; Olz-M = olanzapine treatment range, 7.5, 10, 12.5 mg/day; Olz-H = olanzapine treatment range, 12.5, 15, $17.5 \mathrm{mg} /$ day; $\mathrm{Hal}=$ haloperidol treatment range, $10,15,20 \mathrm{mg} /$ day; $\mathrm{SD}=$ standard deviation; $\mathrm{AE}=\mathrm{acute}$ exacerbation; BPRS = brief psychiatric rating scale; SANS = scale for the assessment of negative symptoms; CGI = clinical global impressions; QLS = quality of life scale.

${ }^{a} p$-values are from $\chi^{2}$ tests for categorical variables and ANOVA for continuous variables. 
Table 2. Patient Disposition: Responder Extension Week 24

\begin{tabular}{|c|c|c|c|c|c|c|c|c|c|c|c|}
\hline \multirow[b]{2}{*}{ Reason } & \multicolumn{2}{|c|}{$\begin{array}{l}\text { Placebo } \\
(n=15)\end{array}$} & \multicolumn{2}{|c|}{$\begin{array}{c}\text { Olz-L } \\
(n=16)\end{array}$} & \multicolumn{2}{|c|}{$\begin{array}{c}\text { Olz-M } \\
(n=19)\end{array}$} & \multicolumn{2}{|c|}{$\begin{array}{c}\text { Olz-H } \\
(n=27)\end{array}$} & \multicolumn{2}{|c|}{$\begin{array}{c}\text { Hal } \\
(n=18)\end{array}$} & \multirow[b]{2}{*}{$p$-Value ${ }^{a}$} \\
\hline & $n$ & $\%$ & $n$ & $\%$ & $n$ & $\%$ & $n$ & $\%$ & $n$ & $\%$ & \\
\hline Completed & 3 & 20.0 & 9 & 56.3 & 9 & 47.4 & 15 & 55.6 & 4 & 22.2 & .051 \\
\hline \multicolumn{12}{|l|}{ Discontinued } \\
\hline Adverse event & 3 & 20.0 & 2 & 12.5 & 3 & 15.8 & 2 & 7.4 & 4 & 22.2 & .668 \\
\hline Lack of efficacy & 7 & 46.7 & 2 & 12.5 & 2 & 10.5 & 6 & 22.2 & 4 & 22.2 & .108 \\
\hline Lost to follow-up & 0 & 0.0 & 1 & 6.3 & 1 & 5.3 & 0 & 0.0 & 1 & 5.6 & .648 \\
\hline Patient decision & 2 & 13.3 & 0 & 0.0 & 3 & 15.8 & 3 & 11.1 & 3 & 16.7 & .570 \\
\hline Protocol variation & 0 & 0.0 & 2 & 12.5 & 1 & 5.3 & 1 & 3.7 & 2 & 11.1 & .543 \\
\hline
\end{tabular}

Abbreviations: Olz-L = olanzapine treatment range, 2.5, 5, or $7.5 \mathrm{mg} /$ day; Olz-M = olanzapine treatment range, 7.5, 10, 12.5 mg/day; Olz-H = olanzapine treatment range, 12.5, 15, $17.5 \mathrm{mg} /$ day; $\mathrm{Hal}=$ haloperidol treatment range, 10, 15, $20 \mathrm{mg} /$ day.

${ }^{a} p$-values are from $\chi^{2}$ tests.

group demonstrated significant mean improvement in SANS summary score compared with the Hal treatment group. Significant within-treatment group improvement in CGI severity score was observed in all but the placebo treatment group. The Olz-M and Olz-H treatment groups showed significant mean improvement in CGI severity score compared with the placebo treatment group. No significant differences in CGI severity scores were observed between the Hal treatment group and the other treatment groups.

\section{Quality of Life for Responders}

Mean changes from baseline to week 24 (LOCF) in the QLS for responders are summarized in Table 4. No significant within-treatment group changes in QLS total or subscale scores were observed for the placebo, Olz-L, or Hal treatment groups. For the Olz-M and Olz-H treatment groups, there were significant within-treatment group changes in QLS total scores and all QLS subscale scores.

Significant mean improvement in all QLS scores at week 24 were observed in the Olz-M treatment group compared with the placebo treatment group. The Olz-H treatment group demonstrated significant mean improvement in QLS total score compared with the placebo treatment group, and this difference appeared to be attributable to improvements in instrumental role category and common objects and activities scores. No significant differences in mean changes in QLS scores were observed between the Hal treatment group and the other treatment groups.

Table 3. Mean Change from Baseline to LOCF Endpoint in Efficacy: Responder Extension Week 24

\begin{tabular}{|c|c|c|c|c|c|c|c|}
\hline \multirow[b]{2}{*}{ Measure } & \multirow[b]{2}{*}{ Treatment } & \multirow[b]{2}{*}{$n$} & \multirow[b]{2}{*}{ Mean } & \multirow[b]{2}{*}{ SD } & \multicolumn{3}{|c|}{$p$-Values } \\
\hline & & & & & $\begin{array}{l}\text { Within } \\
\text { Group }\end{array}$ & vs Placebo & vs Hal \\
\hline \multirow[t]{5}{*}{ BPRS total score } & Placebo & 15 & -4.7 & 15.4 & .381 & & .013 \\
\hline & Olz-L & 16 & -15.0 & 14.3 & .002 & .095 & .382 \\
\hline & Olz-M & 19 & -22.8 & 15.3 & $<.001$ & .004 & .764 \\
\hline & $\mathrm{Olz}-\mathrm{H}$ & 27 & -19.9 & 16.3 & $<.001$ & .003 & .808 \\
\hline & Hal & 18 & -19.9 & 11.3 & $<.001$ & .013 & \\
\hline \multirow[t]{5}{*}{ SANS summary score } & Placebo & 15 & -1.5 & 3.9 & .205 & & .988 \\
\hline & Olz-L & 16 & -2.5 & 5.6 & .088 & .690 & .674 \\
\hline & Olz-M & 19 & -4.7 & 5.2 & .001 & .161 & .138 \\
\hline & $\mathrm{Olz}-\mathrm{H}$ & 27 & -5.5 & 7.0 & $<.001$ & .059 & .049 \\
\hline & Hal & 18 & -2.7 & 5.9 & .030 & .988 & \\
\hline \multirow[t]{5}{*}{ CGI severity score } & Placebo & 15 & -0.1 & 1.1 & .516 & & .209 \\
\hline & Olz-L & 16 & -1.1 & 1.4 & .007 & .092 & .657 \\
\hline & Olz-M & 19 & -1.6 & 1.4 & $<.001$ & .013 & .210 \\
\hline & Olz-H & 27 & -1.2 & 1.5 & $<.001$ & .017 & .297 \\
\hline & Hal & 18 & -0.9 & 1.2 & .004 & .209 & \\
\hline
\end{tabular}

Abbreviations: $\mathrm{LOCF}=$ last observation carried forward; $\mathrm{SD}=$ standard deviation; $\mathrm{vs}=$ versus; $\mathrm{BPRS}=$ brief psychiatric rating scale; $\mathrm{SANS}=$ scale for the assessment of negative symptoms; CGI = clinical global impressions; Olz-L = olanzapine treatment range, 2.5, 5, or 7.5 mg/day; Olz-M = olanzapine treatment range, 7.5, 10, $12.5 \mathrm{mg} /$ day; $\mathrm{Olz}-\mathrm{H}=$ olanzapine treatment range, 12.5, 15, $17.5 \mathrm{mg} /$ day; Hal = haloperidol treatment range, $10,15,20 \mathrm{mg} /$ day. 


\section{Baseline Comparison between Treatment Responders and Nonresponders}

Comparisons were made between treatment responders and nonresponders (regardless of treatment group assignment) on baseline demographics, illness characteristics, and QLS scores (Table 5). Significantly fewer responders had a chronic course of schizophrenia with acute exacerbation at baseline than nonresponders, whereas significantly more responders had $<10$ previous episodes of acute schizophrenia. The age of psychosis onset was significantly greater for responders than nonresponders. Severity of illness for responders at baseline was significantly less than for nonresponders as measured by the efficacy rating scales. Responders also had significantly greater quality of life at baseline than nonresponders, as reflected by the mean QLS scores.

\section{Quality of Life All Patients}

Baseline QLS scores were carried forward for patients not demonstrating a response to treatment (nonresponders) at the completion of the acute phase. Least squares mean change from baseline to week 24 (LOCF) for all patients (responders and nonresponders) is shown in Table 6. Least squares means adjusted for baseline QLS score.

Results from comparisons of the olanzapine treatment groups with the placebo and Hal treatment groups were similar to those observed when only responders were included in the analysis (Table 4); however, a few differences in significance of the results were observed. One difference occurring for all patients was that the Olz-M treatment group showed significant improvement in the QLS intrapsychic foundations score compared with the Hal treatment group. Also, the Olz-H treatment group showed significant mean improvement in QLS interpersonal relations score compared with the placebo treatment group. Furthermore, in the analysis of all patients, the difference between the Olz-L and placebo treatment groups for improvement in QLS common objects and activities was not significant but was in the analysis of responders.

As in the analysis of responders, mean improvement was greatest in the Olz-M treatment group for QLS total and intrapsychic foundations scores. The Olz-M and Olz-H treatment groups had similar improvement on the remaining scores.

Table 4. Mean Change from Baseline to LOCF Endpoint in Quality of Life: Responder Extension Week 24

\begin{tabular}{|c|c|c|c|c|c|c|c|}
\hline \multirow[b]{2}{*}{ Measure } & \multirow[b]{2}{*}{ Treatment } & \multirow[b]{2}{*}{$n$} & \multirow[b]{2}{*}{ Mean } & \multirow[b]{2}{*}{ SD } & \multicolumn{3}{|c|}{$p$-Values } \\
\hline & & & & & $\begin{array}{l}\text { Within } \\
\text { Group }\end{array}$ & vs Placebo & vs Hal \\
\hline \multirow[t]{5}{*}{ QLS total score } & Placebo & 10 & 1.7 & 26.1 & .104 & & .130 \\
\hline & Olz-L & 16 & 6.7 & 26.4 & .097 & .108 & .949 \\
\hline & Olz-M & 16 & 24.6 & 26.2 & .004 & .009 & .380 \\
\hline & $\mathrm{Olz}-\mathrm{H}$ & 22 & 15.5 & 21.5 & $<.001$ & .037 & .813 \\
\hline & Hal & 12 & 4.9 & 25.3 & .715 & .130 & \\
\hline \multirow{5}{*}{ QLS intrapsychic foundations } & Placebo & 10 & 1.2 & 8.7 & .242 & & .475 \\
\hline & Olz-L & 16 & 2.3 & 8.0 & .189 & .179 & .569 \\
\hline & Olz-M & 16 & 8.1 & 10.9 & .014 & .041 & .226 \\
\hline & Olz-H & 22 & 4.2 & 7.7 & .020 & .136 & .555 \\
\hline & $\mathrm{Hal}$ & 12 & 0.9 & 9.4 & .882 & .475 & \\
\hline \multirow[t]{5}{*}{ QLS interpersonal relations } & Placebo & 10 & 1.4 & 11.3 & .121 & & .100 \\
\hline & Olz-L & 16 & 2.5 & 11.3 & .553 & .283 & .445 \\
\hline & Olz-M & 16 & 9.3 & 10.9 & .004 & .029 & .776 \\
\hline & Olz-H & 22 & 5.9 & 10.3 & .009 & .086 & .778 \\
\hline & Hal & 12 & 3.1 & 11.4 & .623 & .100 & \\
\hline \multirow[t]{5}{*}{ QLS instrumental role category } & Placebo & 10 & -0.3 & 5.9 & .844 & & .209 \\
\hline & Olz-L & 16 & 1.5 & 8.5 & .262 & .128 & .887 \\
\hline & Olz-M & 16 & 5.6 & 5.9 & .002 & .021 & .383 \\
\hline & Olz-H & 22 & 4.0 & 5.1 & $<.001$ & .042 & .625 \\
\hline & Hal & 12 & 0.9 & 7.2 & .846 & .209 & \\
\hline \multirow[t]{5}{*}{ QLS common objects and activities } & Placebo & 10 & -0.6 & 3.1 & .891 & & .131 \\
\hline & Olz-L & 16 & 0.4 & 2.4 & .166 & .030 & .594 \\
\hline & Olz-M & 16 & 1.7 & 2.4 & .014 & .014 & .462 \\
\hline & Olz-H & 22 & 1.4 & 2.1 & .005 & .035 & .791 \\
\hline & Hal & 12 & 0.0 & 2.9 & 1.000 & .131 & \\
\hline
\end{tabular}

Abbreviations: $\mathrm{LOCF}=$ last observation carried forward; $\mathrm{SD}=$ standard deviation; vs = versus; QLS = quality of life scale; Olz-L = olanzapine treatment range, $2.5,5$, or $7.5 \mathrm{mg} /$ day; Olz-M = olanzapine treatment range, 7.5, 10, $12.5 \mathrm{mg} /$ day; Olz- $\mathrm{H}=$ olanzapine treatment range, $12.5,15,17.5$ $\mathrm{mg} /$ day; Hal = haloperidol treatment range, $10,15,20 \mathrm{mg} /$ day. 


\section{DISCUSSION}

The psychopathology associated with schizophrenia exerts a considerable impact on patient quality of life (Lehman et al. 1993; Revicki and Murray 1994). Several different instruments have been used to assess the impact of schizophrenia and various mental health interventions on quality of life in patients with chronic schizophrenia (Lehman and Burns 1990; Revicki and Murray 1994). The QLS was developed to evaluate the deficit syndrome in patients with schizophrenia (Heinrichs et al. 1984). The deficit syndrome is associated with impaired functioning and reduced reintegration into the community.

Olanzapine at doses of $10 \pm 2.5 \mathrm{mg} /$ day and $15 \pm 2.5$ $\mathrm{mg} /$ day was significantly more effective than placebo in reducing the severity of psychotic symptoms based on improvement in BPRS total and CGI severity scores over a 24-week period in patients with schizophrenia who responded to acute treatment. Significant withintreatment group improvement in negative symptoms based on the SANS summary score was observed for responders in the Olz-M, Olz-H, and Hal treatment groups. The Olz-H-treated responders demonstrated significant improvement in negative symptoms based on the
SANS summary score compared with the Hal-treated responders.

Patients responding to acute treatment with olanzapine administered at doses of $10 \pm 2.5 \mathrm{mg} /$ day and $15 \pm$ $2.5 \mathrm{mg} /$ day tend to have greater improvement in QLS scores compared with those responding to acute treatment with placebo, haloperidol, and the low dose of olanzapine. The Olz-M and $\mathrm{Olz}-\mathrm{H}$ treatment groups demonstrated mean improvements of 24.6 and 15.5, respectively, in QLS total scores compared with 1.7 for placebo-treated responders, 6.7 for Olz-L-treated responders, and 4.9 for Hal-treated responders. Improvement in quality of life was significant in the Olz-M and $\mathrm{Olz}-\mathrm{H}$ treatment groups compared with the placebo treatment group. Despite the significant within-treatment group improvements in QLS total scores in the Olz-M and Olz-H treatment groups, no significant differences were observed between the olanzapine and Hal treatment groups.

The Olz-M treatment group displayed baseline differences in age, percentage with the paranoid subtype, percentage with $<10$ previous episodes, and quality of life. Power for detecting baseline differences was low due to small sample sizes, and significant baseline differences were not found. Though these baseline differ-

Table 5. Baseline Demographics, Illness Characteristics, and Quality of Life Scale Scores: Responders and Nonresponders

\begin{tabular}{|c|c|c|c|}
\hline Variable & $\begin{array}{l}\text { Nonresponders } \\
\quad(n=234)\end{array}$ & $\begin{array}{l}\text { Responders } \\
\quad(n=76)\end{array}$ & $p$-Value ${ }^{a}$ \\
\hline Male (\%) & 89.3 & 84.2 & .233 \\
\hline Caucasian (\%) & 65.8 & 76.3 & .087 \\
\hline Age, years (mean $\pm S D)$ & $36.1 \pm 9.3$ & $36.1 \pm 10.1$ & .989 \\
\hline \multicolumn{4}{|l|}{ Subtype } \\
\hline Paranoid (\%) & 59.0 & 56.6 & .436 \\
\hline Disorganized (\%) & 5.1 & 9.2 & \\
\hline Undifferentiated (\%) & 35.9 & 34.2 & \\
\hline Chronic course, AE (\%) & 92.7 & 82.9 & .008 \\
\hline \multicolumn{4}{|l|}{ Age of psychosis onset, years } \\
\hline$($ mean $\pm S D)$ & $21.5 \pm 5.4$ & $24.0 \pm 7.0$ & .001 \\
\hline$<10$ Previous episodes & 48.8 & 67.1 & .008 \\
\hline BPRS total (mean $\pm \mathrm{SD})$ & $43.0 \pm 11.4$ & $38.4 \pm 9.7$ & .002 \\
\hline SANS summary (mean \pm SD) & $14.0 \pm 5.2$ & $12.1 \pm 4.1$ & .003 \\
\hline CGI severity (mean $\pm \mathrm{SD})$ & $5.0 \pm 0.8$ & $4.7 \pm 0.8$ & .001 \\
\hline QLS total (mean $\pm \mathrm{SD})$ & $39.5 \pm 22.1$ & $49.8 \pm 21.0$ & $<.001$ \\
\hline \multicolumn{4}{|l|}{ QLS intrapsychic foundations } \\
\hline$($ mean $\pm S D)$ & $15.5 \pm 8.1$ & $18.9 \pm 6.8$ & $<.001$ \\
\hline QLS interpersonal relations & & & \\
\hline$($ mean $\pm S D)$ & $14.4 \pm 8.9$ & $17.8 \pm 9.3$ & .005 \\
\hline $\begin{array}{l}\text { QLS instrumental role category } \\
(\text { mean } \pm \mathrm{SD})\end{array}$ & $4.8 \pm 5.8$ & $6.4 \pm 6.7$ & .048 \\
\hline $\begin{array}{l}\text { QLS common objects and activities } \\
(\text { mean } \pm \text { SD) }\end{array}$ & $4.7 \pm 2.9$ & $6.7 \pm 2.6$ & $<.001$ \\
\hline
\end{tabular}

Abbreviations: $\mathrm{SD}=$ standard deviation; $\mathrm{AE}=$ acute exacerbation; $\mathrm{BPRS}=$ brief psychiatric rating scale; SANS = scale for the assessment of negative symptoms; CGI = clinical global impressions; QLS = quality of life scale.

${ }^{a} p$-values are from $\chi^{2}$ tests for categorical variables and ANOVA for continuous variables. 
ences were not significant, they may have contributed to the group's superior efficacy and safety results.

The absence of significant treatment group differences between the olanzapine and Hal treatment groups may be due to the small sample sizes and the process of collecting QLS data. The QLS was not administered at the end of the acute phase; therefore, followup scores were available only for those patients who entered the responder extension. Of the patients assigned by random allocation to the Olz-H treatment group, $32 \%$ continued into the responder extension and had a baseline and postbaseline QLS score, whereas only $17 \%$ of the patients in the Hal treatment group continued and had the QLS scores. The patients included in the QLS analysis were a very select group who showed evidence of treatment response, with no severe adverse events, and who the investigators decided continued treatment would be beneficial. The small sample sizes reduced the power for observing differences between the olanzapine and Hal treatment groups. When the treatment group comparisons were performed assuming no improvement in nonresponders, the Olz-M demonstrated significant improvement in QLS intrapsychic foundation score compared with the Hal treatment group, with a trend toward significance for the QLS to- tal score. However, caution must be exercised when interpreting these findings, because they assume no change in QLS scores for treatment nonresponders. Other methods of imputing QLS scores for nonresponders may have resulted in different findings.

The changes in QLS scores experienced by patients given olanzapine 7.5 to $17.5 \mathrm{mg}$ /day were comparable to changes seen in clozapine-treated patients (Meltzer et al. 1990). Meltzer et al. (1990) observed improvements of 22.1 points in QLS total scores over 24 weeks in clozapine responders, compared with the improvements of 15.5 to 24.6 points in olanzapine-treated patients over 24 weeks observed in this study.

The group of responders who entered the extension had less impairment at baseline in QLS total scores and in interpersonal relations, intrapsychic foundations, and common objects and activities compared with those patients who did not enter the extension. The treatment responders also had somewhat less severity of illness compared with nonresponders. Consequently, QLS scores may be predictive of treatment response in patients with chronic schizophrenia. Patients with lower QLS scores may have a worse prognosis for treatment response and recovery.

In conclusion, these findings provide support for the positive impact of olanzapine treatment in patients re-

Table 6. Mean Change from Baseline to LOCF Endpoint in Quality of Life: All Patients Week 24

\begin{tabular}{|c|c|c|c|c|c|c|}
\hline \multirow[b]{2}{*}{ Measure } & \multirow[b]{2}{*}{ Treatment } & \multirow[b]{2}{*}{$n$} & \multirow{2}{*}{$\begin{array}{c}\text { LS } \\
\text { Mean }\end{array}$} & \multirow[b]{2}{*}{ SE } & \multicolumn{2}{|c|}{$p$-Values } \\
\hline & & & & & vs Placebo & vs Hal \\
\hline \multirow[t]{5}{*}{ QLS total score } & Placebo & 62 & -0.3 & 1.8 & & .509 \\
\hline & Olz-L & 64 & 1.3 & 1.8 & .504 & 1.000 \\
\hline & Olz-M & 60 & 6.0 & 1.8 & .009 & .051 \\
\hline & $\mathrm{Olz}-\mathrm{H}$ & 62 & 5.6 & 1.8 & .014 & .072 \\
\hline & Hal & 62 & 1.3 & 1.8 & .509 & \\
\hline \multirow[t]{5}{*}{ QLS intrapsychic foundations } & Placebo & 62 & 0.0 & 0.6 & & .734 \\
\hline & Olz-L & 64 & 0.4 & 0.6 & .640 & .901 \\
\hline & Olz-M & 60 & 2.1 & 0.7 & .017 & .040 \\
\hline & $\mathrm{Olz}-\mathrm{H}$ & 62 & 1.6 & 0.6 & .067 & .136 \\
\hline & Hal & 62 & 0.3 & 0.6 & .734 & \\
\hline \multirow[t]{5}{*}{ QLS interpersonal relations } & Placebo & 62 & -0.0 & 0.8 & & .581 \\
\hline & Olz-L & 64 & 0.6 & 0.8 & .545 & .961 \\
\hline & Olz-M & 60 & 2.1 & 0.8 & .037 & .127 \\
\hline & $\mathrm{Olz}-\mathrm{H}$ & 62 & 2.0 & 0.8 & .043 & .139 \\
\hline & Hal & 62 & 0.5 & 0.8 & .581 & \\
\hline \multirow[t]{5}{*}{ QLS instrumental role category } & Placebo & 62 & -0.2 & 0.5 & & .342 \\
\hline & Olz-L & 64 & 0.3 & 0.5 & .385 & .928 \\
\hline & Olz-M & 60 & 1.3 & 0.5 & .012 & .112 \\
\hline & $\mathrm{Olz}-\mathrm{H}$ & 62 & 1.4 & 0.5 & .009 & .091 \\
\hline & Hal & 62 & 0.3 & 0.5 & .342 & \\
\hline \multirow[t]{5}{*}{ QLS common objects and activities } & Placebo & 62 & -0.1 & 0.2 & & .222 \\
\hline & Olz-L & 64 & 0.1 & 0.2 & .414 & 680 \\
\hline & Olz-M & 60 & 0.5 & 0.2 & .016 & .233 \\
\hline & Olz-H & 62 & 0.6 & 0.2 & .003 & .085 \\
\hline & Hal & 62 & 0.2 & 0.2 & .222 & \\
\hline
\end{tabular}

Abbreviations: $\mathrm{LOCF}=$ last observation carried forward; $\mathrm{LS}=$ least squares; $\mathrm{SE}=$ standard error; vs = versus; $\mathrm{QLS}=$ quality of life scale; Olz-L = olanzapine treatment range, 2.5, 5, or $7.5 \mathrm{mg} /$ day; Olz-M = olanzapine treatment range, $7.5,10,12.5 \mathrm{mg} /$ day; Olz- $\mathrm{H}=$ olanzapine treatment range, $12.5,15,17.5 \mathrm{mg} /$ day; $\mathrm{Hal}=$ haloperidol treatment range, 10, 15, $20 \mathrm{mg} /$ day. 
sponding to acute treatment on improvement in overall and negative symptomatology and quality of life. Improvement in QLS scores suggests that olanzapine, at doses of $10 \pm 2.5 \mathrm{mg} /$ day and $15 \pm 2.5 \mathrm{mg} /$ day, improves the quality of life of patients with schizophrenia who responded to acute treatment. This improvement in patient functioning may then lead to an accelerated reintegration into society. Confirmation of these findings requires larger patient samples with follow-up of responders and nonresponders.

\section{REFERENCES}

American Psychiatric Association (1987): Diagnostic and Statistical Manual of Mental Disorders 3rd ed. revised (DSM-III-R). Washington, DC, American Psychiatric Association

Andreasen NC (1982): Negative symptoms in schizophrenia: Definition and reliability. Arch Gen Psychiatry 39:784788

Awad AG, Voruganti L, Heslegrave RJ (1997): Measuring quality of life in patients with schizophrenia. PharmacoEconomics 11(1):32-47

Awad AG (1992): Quality of life of schizophrenia patients on medications and implications for new drug trials. Hosp Community Psychiatry 43:262-265

Beasley CM, Tollefson G, Tran P, Satterlee W, Sanger T, Hamilton S (1996a): Olanzapine versus placebo and haloperidol: Acute phase results of the North American double-blind olanzapine trial. Neuropsychopharmacology 14(2):111-123

Beasley CM Jr, Sanger T, Satterlee W, Tollefson G, Tran P, Hamilton S (1996b): Olanzapine versus placebo: Results of a double-blind, fixed-dose olanzapine trial. Psychopharmacology 124:159-167

Becker M, Diamond R, Sainfort F (1993): A new patient focused index for measuring quality of life in persons with severe and persistent mental illness. Quality Life Res 2:239-251

Bellack AS, Morrison RL, Wixted JT, Mueser KT (1990): An analysis of social competence in schizophrenia. Br J Psychiatry 156:809-818

Breier A, Buchanan RW, Kirkpatrick B, Davis OR, Irish D, Summerfelt A, Carpenter WT (1994): Effects of clozapine on positive and negative symptoms in outpatients with schizophrenia. Am J Psychiatry 151:20-26

Carpenter WT, Hanlon TE, Heinrichs DW, Summerfelt AT, Kirkpatrick B, Levine J, Buchanan RW (1990): Continuous versus targeted medication in schizophrenic outpatients: Outcome results. Am J Psychiatry 147:11381148

Carpenter WT, Heinrichs DW, Hanlon TE (1981): Methodologic standards for treatment outcomes research in schizophrenia. Am J Psychiatry 138:465-471

Chouinard G, Jones B, Remington G, Bloom D, Addington D, MacEwan GW, Labelle A, Beauclair L, Arnott W (1993): A Canadian multicenter placebo-controlled study of fixed doses of risperidone and haloperidol in the treatment of chronic schizophrenic patients. J Clin Psychopharmacol 13:25-40

Collins EJ, Hogan TP, Himansu D (1991): Measurement of therapeutic response in schizophrenia: A critical survey. Schizophr Res 5:249-253

Guy W (1976): ECDEU Assessment manual for psychopharmacology. Publication ADM 76-338. Rockville, MD, National Institute of Mental Health, U.S. Department of Health, Education, and Welfare

Heinrichs DW, Hanlon TE, Carpenter WT (1984): The quality of life scale: An instrument for rating the schizophrenic deficit syndrome. Schizophr Bull 10:388-398

Kane J, Honigfeld G, Singer J, Meltzer H (1988): Clozapine for the treatment-resistant schizophrenic: A doubleblind comparison with chlorpromazine. Arch Gen Psychiatry 45:789-796

Kane J, Marder SR (1993): Psychopharmacologic treatment of schizophrenia. Schizophr Bull 19:287-302

Lehman AF, Postrado LT, Rachuba LT (1993): Convergent validation of quality of life assessments for persons with severe mental illness. Quality Life Res 2:327-333

Lehman AF, Burns BJ (1990): Severe mental illness in the community. In Spilker B (ed), Quality of Life Assessments in Clinical Trials. New York, Raven Press

Lehman AF, Possidente S, Hawker F (1986): The quality of life of chronic patients in a state hospital and in community residences. Hosp Community Psychiatry 37(9):901-907

Marder SR, Meibach RC (1994): Risperidone in the treatment of schizophrenia. Am J Psychiatry 151:825-835

Meltzer HY, Burnett S, Bastani B, Ramirez LF (1990): Effects of six months of clozapine treatment on the quality of life of chronic schizophrenic patients. Hosp Community Psychiatry 41:892-897

Moore NA, Calligaro DO, Wong DT, Bymaster F, Tye NC (1993): The pharmacology of olanzapine and other new antipsychotics. Curr Opinion Investigational Drugs 2:281293

Moore NA, Tupper DE, Hotten TM (1994): Olanzapine. Drugs Future 19:114-117

Mueser K, Douglass M, Bellack A, Morrison R (1991): Assessment of enduring deficit and negative symptom subtypes in schizophrenia. Schizophr Bull 17:565-582

Patrick D, Erickson P (1993): Health Status and Health Policy: Quality of Life in Health Care Evaluation and Resource Allocation. New York, Oxford University Press, p 478

Revicki DA, Murray MI (1994): Assessing health-related quality of life outcomes of drug treatments for psychiatric disorders. CNS Drugs 1:465-476

Tollefson GD, Beasley CM, Tran PV, Street JS, Krueger JA, Tamura RN, Graffeo KA, Thieme ME (1997): Olanzapine versus haloperidol in the treatment of schizophrenia, schizoaffective and schizophreniform disorders: Results of an intentional collaborative trial. Am J Psychiatry 154:457-465

Woerner MG, Mannuza S, Kane JM (1988): Anchoring the BPRS: An aid to improved reliability. Psychopharmacol Bull 24:112-117 